\title{
High Speed Laser Micro Processing Using High Brilliance Continuous Wave Laser Radiation
}

\author{
Horst EXNER, Lars HARTWIG, Robby EBERT, Sascha KLOETZER, \\ Andre STREEK, Joerg SCHILLE, Udo LOESCHNER \\ University of Applied Sciences Mittweida, Laser Application Centre, \\ Technikumplatz 17, 09648 Mittweida, Germany \\ E-mail: exner@hs-mittweida.de
}

\begin{abstract}
Laser micro processing using a high power single-mode continuous wave fibre laser in combination with a fast galvanometer scanner as well as an ultra fast polygon scan systems was investigated. As a key technology in high rate laser ablation a maximum laser power up to $3 \mathrm{~kW}$ and scan speeds up to $18,000 \mathrm{~m} / \mathrm{min}$ were applied. With the ultra fast laser beam deflection and a small laser focal spot diameter of $21 \mu \mathrm{m}$ laser dwell times less than 100 nanoseconds were achieved. As a result laser intensities comparable to the q-switched lasers in the range of $10^{8} \mathrm{~W} / \mathrm{cm}^{2}$ were irradiated on stainless steel, copper, and tungsten. The paper discusses the influence of the significant laser processing parameters, such as laser power, scan speed and scan number, on the ablation rate and the machining qualities. Furthermore initial ablation structures and micro-slits will be presented.
\end{abstract}

DOI:10.2961/jlmn.2012.01.0023

Keywords: high speed, laser ablation, brilliant laser, micro processing, ultra fast, polygon scanner

\section{Introduction}

Recently, the use of brilliant laser sources in form of high power single-mode fibre lasers has been increasingly investigated. In several scientific studies high speed laser welding and high speed laser cutting were of particular interest [1-4]. Due to the high beam quality, long distance focussing objectives and high speed scan systems could be applied. Furthermore remote laser cutting with a focal spot diameter less than $100 \mu \mathrm{m}$ has been demonstrated successfully $[5,6]$.

However, the application of high power continuous wave laser radiation in the fields of laser micro processing not only requires high brilliant laser beam qualities, but also a considerably reduced laser dwell time. Longer laser dwell times cause a high laser energy input to the work piece and detrimental material melting and deep penetration effects occur accompanied by material bulges and burr formations.

Short laser material interaction times can be realised by both small focus spot sizes and ultra fast beam deflection. Furthermore the laser intensity must be high enough for material ablation. The use of commercially available high brilliant fibre laser systems facilitate small focus spot sizes and with laser output powers of some $\mathrm{kW}$ laser intensities of $10^{8} \mathrm{~W} / \mathrm{cm}^{2}$ can be reached. Fast and ultra fast laser beam deflection is provided with the implementation of innovative scan systems, such as special designed galvanometer scanner and the polygon mirror scanner technology.

In this study high speed laser micro processing with laser dwell times less than $100 \mathrm{~ns}$ and laser intensities in the range of q-switched lasers was investigated. The influence of the processing parameters on the ablation process will be discussed by means of stainless steel, copper and tungsten metal sheets. Machining examples will be presented to demonstrate the possibilities and limits of the technology in high speed laser micro processing.

\section{Experimental details}

In the experiments a high brilliant single mode fibre laser YLR-3000 SM (IPG) was applied. The maximum cw laser output power of the randomised polarised laser radiation was $3 \mathrm{~kW}$ with a times-diffraction-limit-factor of $\mathrm{M}^{2}<1.2$. The laser beam switching frequency was $2 \mathrm{kHz}$ with the minimal laser on time of $250 \mu \mathrm{s}$. The laser parameters are summarised in Table 1.

Table 1: Laser parameter.

\begin{tabular}{ccc}
\hline wavelength & min. pulse duration & pulse repetition frequency \\
\hline$\lambda[\mathrm{nm}]$ & $\mathrm{t}[\mu \mathrm{s}]$ & $\mathrm{f}[\mathrm{kHz}]$ \\
1070 & 250 & $\mathrm{cw}-\max .2 \mathrm{kHz}$ \\
\hline
\end{tabular}

Fast deflection of the laser beam was reached by implementation of a high aperture galvanometer scanner with a maximum scan speed of 1,200 $\mathrm{m} / \mathrm{min}$ (Superscan SC-30Y-Dig2, Raylase). Furthermore a special designed polygon mirror scanner was applied in the experiments. It consists of a polygon mirror (Lincoln Laser) for ultra fast beam deflection in X-direction and a galvanometer mirror to move up the laser beam in Y-direction.

Table 2: Technical data of the scan systems.

\begin{tabular}{ccc}
\hline & $\begin{array}{c}\text { Polygon mirror } \\
\text { scanner }\end{array}$ & $\begin{array}{c}\text { Galvanometer } \\
\text { scanner }\end{array}$ \\
\hline focal distance $[\mathrm{mm}]$ & 230 & 230 \\
laser spot size $\mathrm{d}_{86}[\mu \mathrm{m}]$ & 21 & 21 \\
max. scan speed & 18,000 & 1,200 \\
$\quad[\mathrm{~m} /$ min] \\
max. laser power on \\
$\begin{array}{c}\text { work piece }[\mathrm{kW}] \\
\text { max. intensity on }\end{array}$ & 1.99 & 2.64 \\
$\begin{array}{c}\text { work piece }\left[\mathrm{W} / \mathrm{cm}^{2}\right] \\
\text { min. dwell time }[\mu \mathrm{s}]\end{array}$ & $5.7 * 10^{8}$ & $7.6^{*} 10^{8}$ \\
\hline
\end{tabular}


The experimental setup was completed by a $230 \mathrm{~mm}$ telecentrical f-theta objective to focus the laser beam. The $1 / \mathrm{e}^{2}$ focal spot size was measured of $\mathrm{d}_{86}=21 \mu \mathrm{m}$, using the Micro Spot Monitor (Primes). The laser dwell time as the interaction time of the laser beam with the material was estimated by dividing the $1 / \mathrm{e}^{2}$ spot size of the laser beam by the laser scan speed. Technical details of the scanner systems are summarised in Table 2.

Laser ablation experiments were conducted using different materials, such as $1 \mathrm{~mm}$ thick stainless steel 1.4301, $1 \mathrm{~mm}$ thick copper, and $0.5 \mathrm{~mm}$ thick tungsten metal sheets. In all the experiments the laser beam was focused on the sample surface. Ablation cavities were produced by multiple line-scans of $50 \mathrm{~mm}$ length. Periodically the laser process was interrupted after each ablated single structure by a time delay of $500 \mathrm{~ms}$. That way prevents thermal lens effects caused by the overheating of the focusing optic.

Ablation structures obtained were evaluated by cross section photographs taken by a digital microscopy (VHX100, Keyence). The ablation depths and the clear ablated areas were determined to calculate the ablation rates. However, re-deposition and re-solidification of molten material reduces the ablation depth and the ablated cross sectional area and result in lowered ablation rates.

\section{Results and discussion}

\subsection{Characteristics and effects using ultra fast scan speed}

Application of ultra fast scan systems with scan speeds much faster than $1,000 \mathrm{~m} / \mathrm{min}$ in combination with small focus spot sizes causes very short dwell times, in which the laser beam can interact with the material surface. Table 3 illustrates laser dwell times, calculated with different scan speeds, the laser spot size was kept constant of $21 \mu \mathrm{m}$.

Table 3: Laser dwell time for different scan speeds.

\begin{tabular}{cc}
\hline scan speed $[\mathrm{m} / \mathrm{min}]$ & laser dwell time $[\mathrm{ns}]$ \\
\hline 1,200 & 1050 \\
2,250 & 560 \\
4,500 & 280 \\
9,000 & 140 \\
13,500 & 93 \\
18,000 & 70 \\
\hline
\end{tabular}

Primarily the experiments show the ablation behaviour comparably to short pulsed laser material processing. Despite the high irradiated laser intensity, the laser dwell time seems to be too short for a sufficient laser energy deposition to evaporate the material due to the high processing speeds. Hence the impact of the laser dwell time on the laser process was theoretically studied exemplarily on tungsten by a simplified temperature field calculation using the finite difference method. Therefore the time dependent heat conduction equation was transformed in a system of first-order differential equations. As already shown in [7] the irradiated solid was subdivided into limited numbers of both radial symmetrical hollow cylinders surrounding the axis of the laser beam and sublayers parallel to the surface. By integration over the volume of each of the resulting elements, a system of ordinary non linear differential equa- tions of first order related with time to axial symmetrical laser power density distribution was obtained accordingly

$$
\frac{d T_{i j}}{d t}=\frac{\dot{q}_{i j}^{c}+\dot{q}_{i j}^{r}}{C_{i j}}+\frac{I_{i j}}{\Delta Z \cdot C_{i j}}
$$

with $\dot{q}$ as the heat flow density referred to the heat conduction (index c) and heat radiation (index $r$ ):

$$
\begin{aligned}
\dot{q}_{i j}^{c}=B_{i-1, j}\left(T_{i-1, j}-T_{i j}\right)+B_{i+1, j}\left(T_{i+1, j}-T_{i j}\right) & \\
& +B_{i, j-1}\left(T_{i, j-1}-T_{i j}\right) B_{i, j+1}\left(T_{i, j+1}-T_{i j}\right),
\end{aligned}
$$
$\dot{q}_{i j}^{r}= \begin{cases}\varepsilon_{i j} \sigma_{i j}\left(T_{i j}^{4}-T_{a}^{4}\right) / \Delta Z & \text { for elements } i j \text { on the surface } \\ 0 & \text { for elements } i j \text { in the volume }\end{cases}$

The index $\boldsymbol{i}$ and $\boldsymbol{j}$ indicate the sublayer and the hollow cylinder with the temperature $\boldsymbol{T}_{i j}$ in the centre of the element, $\boldsymbol{t}$ the time, $\boldsymbol{B}_{i j}$ the heat coupling coefficient, $\boldsymbol{I}_{i j}$ the laser intensity absorbed in the element, $\mathbf{C}_{i j}$ the heat capacity per unit volume, $\Delta \boldsymbol{Z}_{\boldsymbol{i}}$ the height of the hollow cylinders in the layer $i$, $\varepsilon_{i j}$ the emissivity, $\sigma_{i j}$ the Stefan-Boltzmann constant, and $\boldsymbol{T}_{\boldsymbol{a}}$ the ambient temperature. The differential equation system is solved by the finite difference method and temperature calculations were carried out using a computer temperature analysis program.

Initially a time-dependent temperature calculation was conducted under assumption of a laser dwell time of 93 ns. That temporal pulse profile was calculated with a Gaussian laser beam of $21 \mu \mathrm{m}$ spot size and a scan speed of 13,500 $\mathrm{m} / \mathrm{min}$ (Fig. 1). Under consideration of a reflectivity of the ideal tungsten surface $\mathrm{R}=0.59$ given in [8], with the laser power of $330 \mathrm{~W}$ a laser intensity of $9.5^{*} 10^{7} \mathrm{~W} / \mathrm{cm}^{2}$ was irradiated on the tungsten surface.

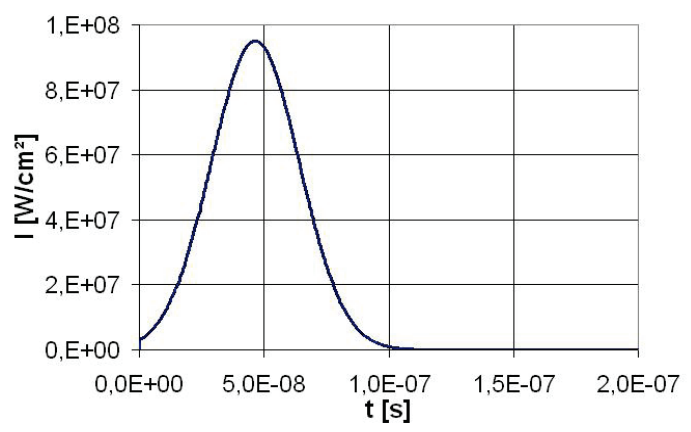

Fig. 1: Temporal pulse shape of laser irradiation using a Gaussian laser beam with a spot size of $21 \mu \mathrm{m}$ and a scan speed of $13,500 \mathrm{~m} / \mathrm{min}$, laser dwell time was calculated of $93 \mathrm{~ns}$.

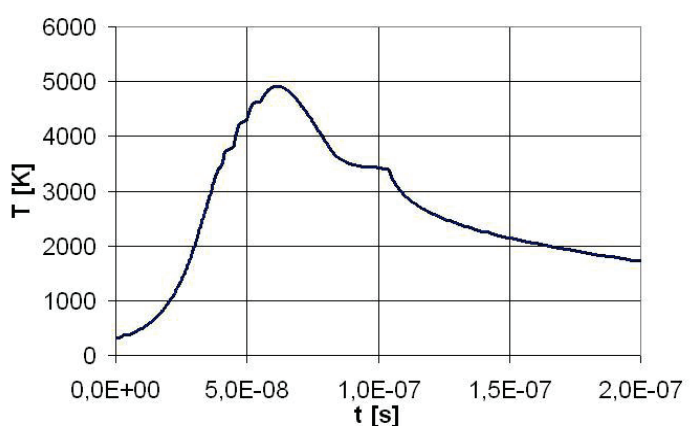

Fig. 2: Calculated temperature profile on tungsten within the laser focus after laser irradiation of $9.5 * 10^{7} \mathrm{~W} / \mathrm{cm}^{2}$. 
However, the temperature calculation elucidate that the evaporation temperature of tungsten of $5828 \mathrm{~K}$ is not fully reached in spite of the high impinged laser intensities (Fig. 2). In contrast to the theoretical consideration, laser processing with laser parameters used in the simulation exhibit a partial material ablation, clearly recognisable in Fig. 3 as a line of dots.

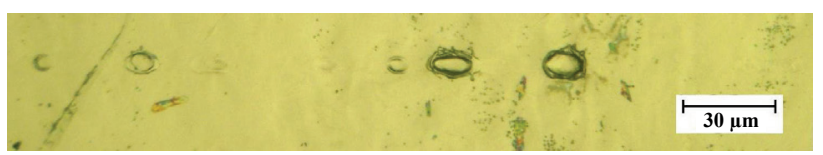

Fig. 3: Digital photograph of a laser processed tungsten surface, $\mathrm{v}=13,500 \mathrm{~m} / \mathrm{min}, \mathrm{P}=330 \mathrm{~W}, 1 \mathrm{scan}$.

Subsequently the temperature calculation was revised. Instead of the ideal tungsten surface a technical surface was taken into calculation. The reflectivity of the technical tungsten surface was assumed of $R=0.2$ due to the higher surface roughness, deposited particles and impurities. The calculation with this realistic reflectivity value gives a temperature rise which exceeds the evaporation temperature of tungsten. According to the calculated temperature profile, in case of the temperatures exceed the evaporation temperature, the ablation depths and the thickness of the molten layer were estimated of $50 \mathrm{~nm}$ and $800 \mathrm{~nm}$, respectively. Thus, the simulation outcomes correlate to the experimental results obtained. In consequence, locally induced material evaporation due to high absorptivity centres and surface defects can be assumed.

Laser irradiation using a laser power of $990 \mathrm{~W}$ led to higher temperature gradients due to the much higher irradiated laser intensity of $2.85 * 10^{8} \mathrm{~W} / \mathrm{cm}^{2}$. With a scan speed of $13,500 \mathrm{~m} / \mathrm{min}$ the temperature calculation predicted $650 \mathrm{~nm}$ deep and $25 \mu \mathrm{m}$ wide molten layers, the ablation depth was assumed of $50 \mathrm{~nm}$. In real the achieved kerf width of $28 \mu \mathrm{m}$ was broader than the laser spot size of $21 \mu \mathrm{m}$. Fig. 4 illustrates a steady ablation groove.

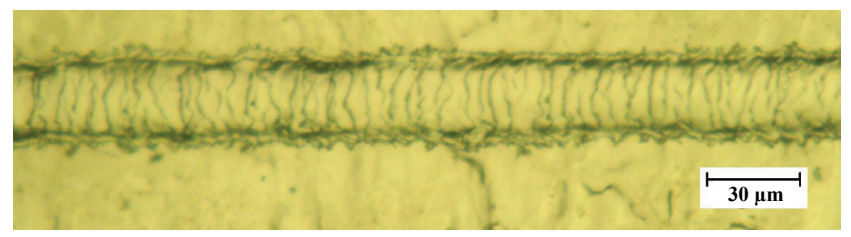

Fig. 4: Digital photograph of a laser processed tungsten surface, $\mathrm{v}=13,500 \mathrm{~m} / \mathrm{min}, \mathrm{P}=990 \mathrm{~W}, 1 \mathrm{scan}$.

Alternatively, laser irradiation with a laser power of $330 \mathrm{~W}$, but lowered scan speeds of $4,500 \mathrm{~m} / \mathrm{min}$ yields to uniform ablation cavities (Fig. 5). For that case a laser dwell time of $280 \mathrm{~ns}$ was calculated. The temperature calculation indicated a thickness of the molten layer of $1 \mu \mathrm{m}$.

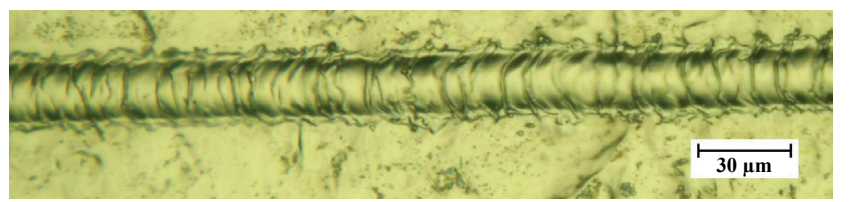

Fig. 5: Digital photograph of a laser processed tungsten surface, $\mathrm{v}=4,500 \mathrm{~m} / \mathrm{min}, \mathrm{P}=330 \mathrm{~W}, 1$ scan.

Because of the lower irradiated laser intensity the width of the ablation kerf fits to the laser focus diameter of $21 \mu \mathrm{m}$.
The experimental results are in good agreement with theoretical values obtained using the simplified temperature calculation by considering pulsed laser irradiation. In future temperature calculation will be carried out using an enhanced model with deflected laser beams.

\subsection{Considerations of cw laser ablation using ultra fast scan speed}

Depending on the irradiated laser power, near-surface ablation widths became considerably wider than the laser focus spot size (Fig. 4, 6 left). The melting zone was broadened with the higher laser energy input due to either the higher impinged laser power or the reduced scan speed or both. In each case the energy input per unit length as the quotient of irradiated laser power and scan speed was increased. The broadening effect was also confirmed by the simulation outcomes. The width of the melting zone of the ablated cavity in Fig. 6 was measured of approx. $45 \mu \mathrm{m}$. Considering the applied processing parameters in theoretical calculations, the width of the melting zone was determined of $26 \mu \mathrm{m}$. Furthermore the observed strong plasma formation can be assumed as another broadening effect.
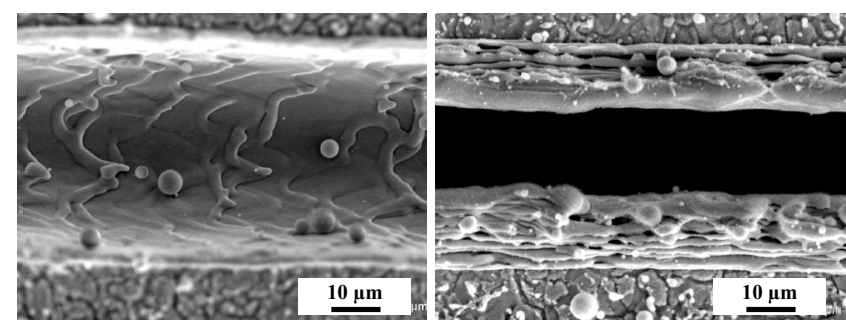

Fig. 6: SEM images of laser processed stainless steel surface, $\mathrm{P}=660 \mathrm{~W}, \mathrm{v}=4,500 \mathrm{~m} / \mathrm{min}$, left 10 scans, right 25 scans.

Ablation products were observed in vaporous and liquid mixed phase regimes, whereas the ratio of the melting grows with the increase of the ablation depths. Due to the high surface tension, the ejected molten material resolidified into small spheres with diameters ranging between 1 and $5 \mu \mathrm{m}$. The higher the scan speed the smaller the sphere diameter. The molten material was ejected out of the ablated cavity against the scan direction due to the formation of a backwards directed vapour-gas channel. With deeper ablation depths a higher amount of re-solidified material was deposited in layers on the cavity sidewalls. As a result little cutting kerfs much smaller than the laser focus spot size with widths ranging between $16 \mu \mathrm{m}$ (Fig. 6, right) and $3 \mu \mathrm{m}$ (Fig. 17) as the smallest ones were obtained.

\subsection{Ablation behaviour of stainless steel 1.4301}

First investigations were carried out utilising the galvanometer scanner with a scan speed of $1,200 \mathrm{~m} / \mathrm{min}$ (Fig. 7,8 ). Figure 7 reveals a highly reliable ablation process up to ten scans and ablation depths of $200 \mu \mathrm{m}$ were achieved. For high speed processing the results indicate a laser power threshold of at least $1.5 \mathrm{~kW}$ to achieve ablation depths considerably deeper than $500 \mu \mathrm{m}$. A further increase of the irradiated laser power from $1.76 \mathrm{~kW}$ to $2.65 \mathrm{~kW}$ did not enhance the ablation rate adequately. The effective cutting speed to cut a metal sheet of $0.5 \mathrm{~mm}$ thickness was determined of $60 \mathrm{~m} / \mathrm{min}$. Therefore 20 scans and a laser power between $1.32 \mathrm{~kW}$ and $2.64 \mathrm{~kW}$ were irradiated. In contrast to reported results achieved with a scan speed of 
$900 \mathrm{~m} / \mathrm{min}$ [1], with $1,200 \mathrm{~m} / \mathrm{min}$ a $25 \%$ lowered effective cutting speed was obtained.

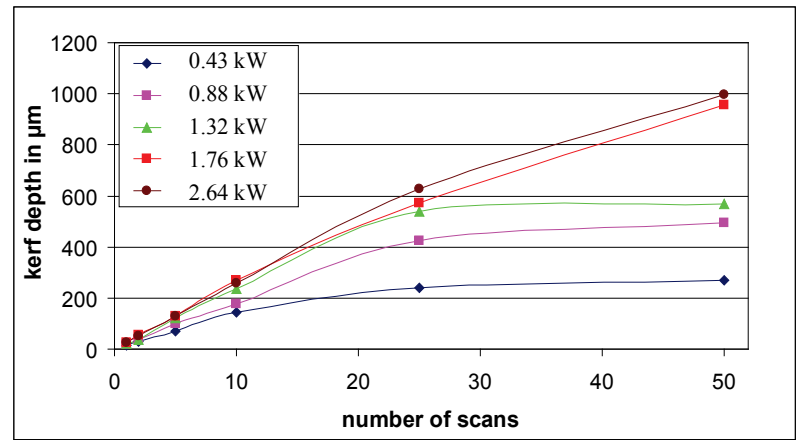

Fig. 7: Kerf depth vs. scan number and laser power in $1 \mathrm{~mm}$ thick stainless steel, processing speed $\mathrm{v}=1,200 \mathrm{~m} / \mathrm{min}$, galvanometer scanner.

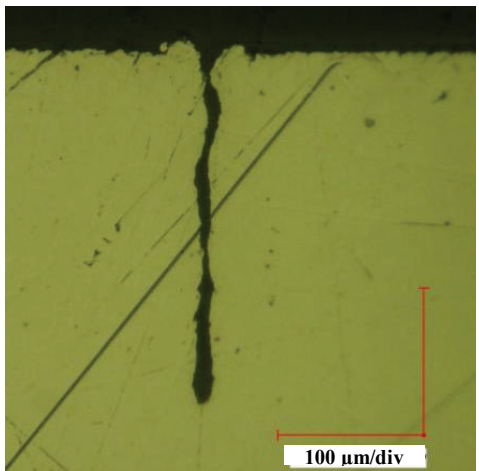

Fig. 8: Cutting kerf in $1 \mathrm{~mm}$ thick stainless steel, $\mathrm{P}=430 \mathrm{~W}$, processing speed $\mathrm{v}=1,200 \mathrm{~m} / \mathrm{min}, 25$ scans, galvanometer scanner.

Fig. 9 exhibits the required energy input per unit length to achieve a designated ablation depth depending on irradiated laser power; the energy per unit length was cumulated with the scan number. A significant decrease of the process efficiency with the higher irradiated laser power is recognisable. Accordingly, the ablation depth of $100 \mu \mathrm{m}$ can be achieved by irradiation of a minor laser power of $430 \mathrm{~W}$ and the accumulated energy per unit length of $140 \mathrm{~J} / \mathrm{m}$ respectively.

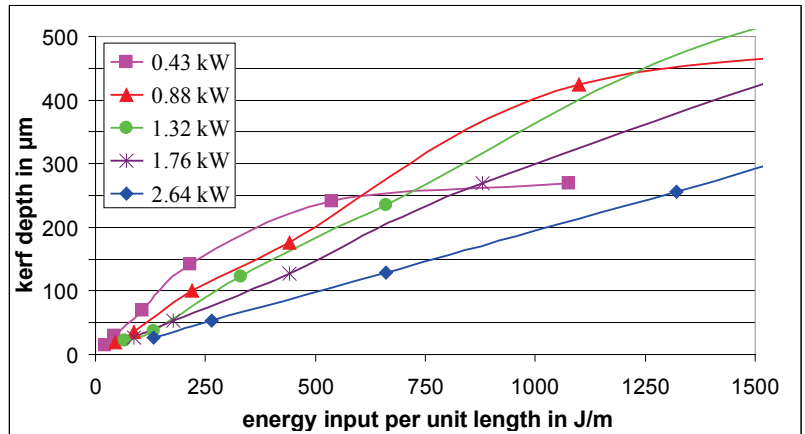

Fig. 9: Kerf depth vs. energy input per unit length and laser power in $1 \mathrm{~mm}$ thick stainless steel, processing speed $\mathrm{v}=1,200 \mathrm{~m} / \mathrm{min}$, galvanometer scanner.

However, irradiation of $2.64 \mathrm{~kW}$ laser power requires an accumulated energy input per unit length of about $550 \mathrm{~J} / \mathrm{m}$ to achieve an ablation depth of $100 \mu \mathrm{m}$. Further- more a disproportional increase of the accumulated energy input can be observed above a threshold value, such as a laser power of $430 \mathrm{~W}$ and $150 \mu \mathrm{m}$ ablation depth. As far as the laser power exceeds a threshold value, the kerf depth increases linearly with the accumulated energy. A homogeneous ablation process independent from the ablation depth can be assumed. Subsequently the ablation process became progressively less efficient and the ablation depth increases insignificantly up to $250 \mu \mathrm{m}$, in spite of the high laser energy input per unit length.

The first experimental outcomes of the investigations using the ultra fast polygon scanner system summarises Fig. 10. Qualitatively the results conform to the results obtained with the galvanometer scanner, in spite of the extremely short laser dwell times of $70 \mathrm{~ns}$ in minimum, achieved with an ultra fast scan speed of $18,000 \mathrm{~m} / \mathrm{min}$. With a laser power of $330 \mathrm{~W}$ and $500 \mathrm{~W}, 100$ scans and a scan speed of $13,500 \mathrm{~m} / \mathrm{min}$ the maximum ablation depths were determined of $80 \mu \mathrm{m}$ and $115 \mu \mathrm{m}$ respectively. With higher laser power the limit of the achievable ablation depth was not specified due to insufficient scan numbers.

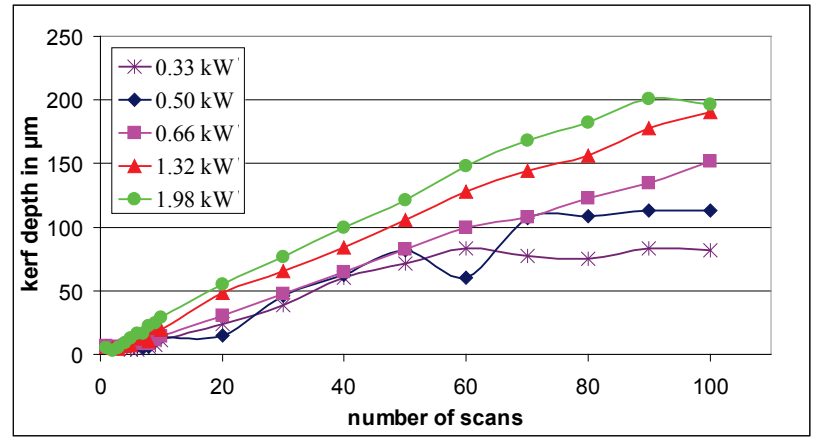

Fig. 10: Kerf depth vs. scan number and laser power in $1 \mathrm{~mm}$ thick stainless steel, processing speed $\mathrm{v}=13,500 \mathrm{~m} / \mathrm{min}$, polygon scanner.

The analysis of the accumulated energy input per unit length shown in Fig. 11 implies good qualitatively and quantitatively agreements with results achieved using the galvanometer scanner with $1,200 \mathrm{~m} / \mathrm{min}$ scan speed. In both cases and a laser power of $1.32 \mathrm{~kW}$ an energy input per unit length of $280 \mathrm{~J} / \mathrm{m}$ was required to achieve ablation depths of about $100 \mu \mathrm{m}$.

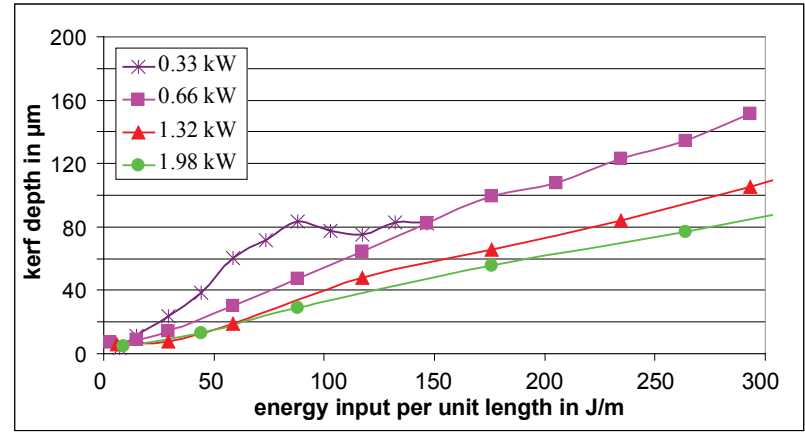

Fig. 11: Kerf depth depending on energy input per unit length in $1 \mathrm{~mm}$ thick stainless steel, processing speed $\mathrm{v}=13,500 \mathrm{~m} / \mathrm{min}$, polygon scanner. 
As shown in Fig. 12, the ablation rate per scan number decreases with increasing scan speed. With the laser power of $1.32 \mathrm{~kW}$ a maximal ablation depth of $550 \mu \mathrm{m}$ was achieved. The effective processing speed with due regards to scan numbers and $100 \mu \mathrm{m}$ ablation depths was approx. $300 \mathrm{~m} / \mathrm{min}$ in maximum, investigated for processing speeds ranging between 1,200 and $18,000 \mathrm{~m} / \mathrm{min}$.

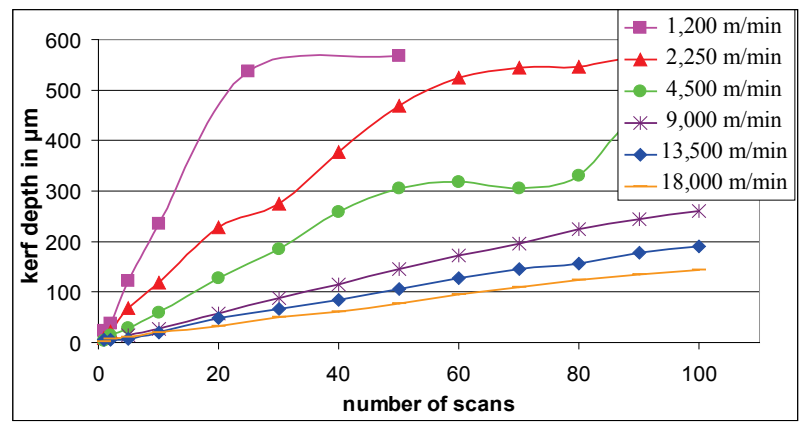

Fig. 12: Kerf depth vs. scan number, $1 \mathrm{~mm}$ thick stainless steel, laser power $\mathrm{P}=1.32 \mathrm{~kW}$, polygon scanner.

To achieve ablation depths of $100 \mu \mathrm{m}$ the energy per unit length was required of $280 \mathrm{~J} / \mathrm{m}$, almost independent from scan speeds as obviously in Fig. 13. Only in deeper ablation depths a variance of the values was observed.

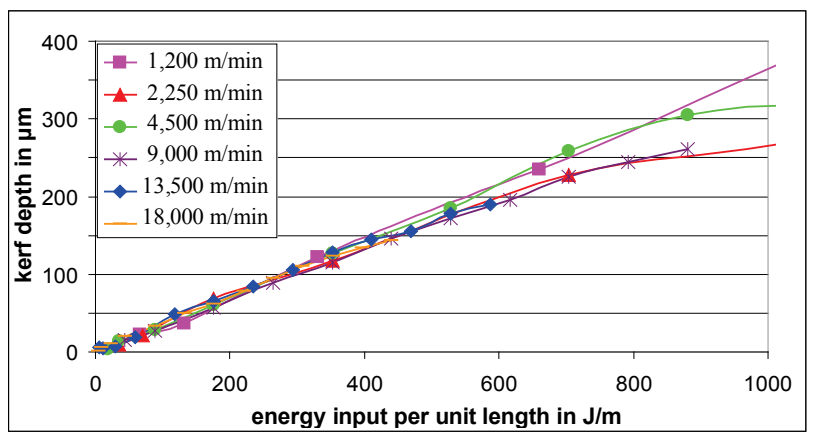

Fig. 13: Kerf depth vs. energy input per unit length, $1 \mathrm{~mm}$ thick stainless steel, laser power $\mathrm{P}=1.32 \mathrm{~kW}$, polygon scanner.

The volume-ablation rate depends on the ablation depth, impinged laser power and scan speed; it decreases with increasing ablation depth and scan speed, and increases with higher irradiated laser power. With scan speeds of $900 \mathrm{~m} / \mathrm{min}$ the volume-ablation rates change dramatically between 900 and $2,400 \mathrm{~mm}^{3} / \mathrm{min}$, with scan speeds of $2,250 \mathrm{~m} / \mathrm{min}$ between 300 and $1,800 \mathrm{~mm}^{3} / \mathrm{min}$, and with $18,000 \mathrm{~m} / \mathrm{min}$ between 60 and $1,200 \mathrm{~mm}^{3} / \mathrm{min}$. Thus, the ablation efficiency was increased up to an optimum value due to the higher amount of melting, which enhances the ablation process. The irradiation of higher laser power led to a stronger material evaporation accompanied by lowered ablation rates.

\subsection{Laser ablation of copper and tungsten}

Furthermore laser ablation of copper and tungsten was investigated, and referred to results achieved on stainless steel. Both materials are characterised by extreme material properties. Copper is characterised by a high reflectivity and high heat conductivity, tungsten has a high melting and evaporation temperature. In contrast, stainless steel is char- acterised by less heat conductivity and a considerably lowered ablation threshold.

As shown in Fig. 11 on stainless steel, ablation depths of $80 \mu \mathrm{m}$ were obtained with a laser power of $0.33 \mathrm{~kW}$ and a scan speed of $13,500 \mathrm{~m} / \mathrm{min}$. The same laser processing parameter irradiated on copper and tungsten surfaces causes an inconsistent ablation process. To achieve the ablation depths $60 \mu \mathrm{m}$, as much as double of the laser power irradiated on stainless steel $(0.66 \mathrm{~kW})$ is required for copper and tungsten (Fig. 14, 15).

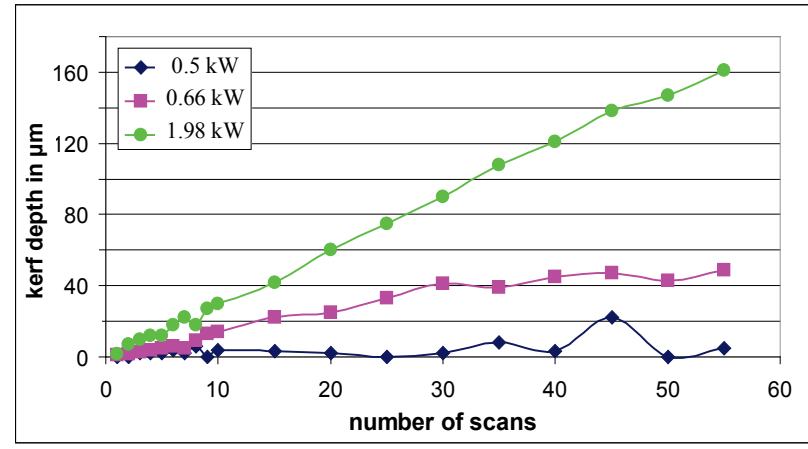

Fig. 14: Kerf depth vs. scan number and laser power, $1 \mathrm{~mm}$ thick copper, scan speed $\mathrm{v}=13,500 \mathrm{~m} / \mathrm{min}$, polygon scanner.

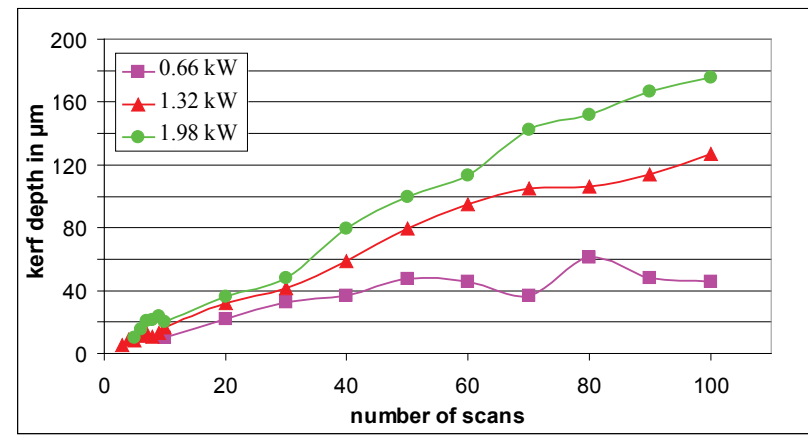

Fig. 15: Kerf depth vs. scan number and laser power, $0.5 \mathrm{~mm}$ thick tungsten, scan speed $\mathrm{v}=13,500 \mathrm{~m} / \mathrm{min}$, polygon scanner.

In comparison to copper and tungsten, in stainless steel the achieved volume-ablation rate and ablation depth were 5 and respectively 2 times higher (Table 4 ).

Table 4: Kerf depth and ablation rate obtained for stainless steel, copper and tungsten; $\mathrm{v}=13,500 \mathrm{~m} / \mathrm{min}, \mathrm{P}=0.66 \mathrm{~kW}, 50$ scans.

\begin{tabular}{cccc}
\hline & Stainless steel & Copper & Tungsten \\
\hline $\begin{array}{c}\text { kerf depth in } \\
\mu \mathrm{m}\end{array}$ & 82 & 43 & 47 \\
$\begin{array}{c}\text { volume ablation } \\
\text { rate in } \mathrm{mm}^{3} / \mathrm{min}\end{array}$ & 318 & 60 & 54 \\
\hline
\end{tabular}

With the higher laser power of $1.98 \mathrm{~kW}$ Table 5 illustrates a less difference between the ablation rates. Ablation depths per scan were observed between 2 and $3 \mu \mathrm{m}$, and even on copper the highest ablation depth was detected. At the higher laser power the volume-ablation rate of stainless steel was only increased by factor of 3 and 4 , related to copper and tungsten respectively.

The seeming contrast between the considerably higher volume-ablation rate on stainless steel in comparison to copper and tungsten but otherwise approximately similar ablation depths is explainable by considering the widths of 
the ablated cavities. With the higher irradiated laser power, in stainless steel significant broader ablation widths were observed. Therefore a significantly lowered deposition of molten material on the sidewalls of the ablated cavities in stainless steel can be assumed in comparison to copper and tungsten.

Table 5: Kerf depth and ablation rate obtained on stainless steel, copper and tungsten, $\mathrm{v}=13,500 \mathrm{~m} / \mathrm{min}, \mathrm{P}=1.98 \mathrm{~kW}, 50$ scans.

\begin{tabular}{cccc}
\hline & Stainless steel & Copper & Tungsten \\
\hline $\begin{array}{c}\text { kerf depth in } \\
\mu \mathrm{m}\end{array}$ & 121 & 149 & 99,7 \\
$\begin{array}{c}\text { volume ablation } \\
\text { rate in } \mathrm{mm}^{3} / \mathrm{min}\end{array}$ & 990 & 318 & 234 \\
\hline
\end{tabular}

\subsection{Laser micro structuring}

Fig. 17 and 18 illustrate laser generated micro structures obtained in stainless steel using the polygon scanner. In Fig. 17 the distance between the single cavities was $25 \mu \mathrm{m}$. The width of $13 \mu \mathrm{m}$ near the surface was considerably smaller than the focus spot size. Re-deposition of molten material on the walls of the ablation cavities lifts the height of the walls over the height of the not irradiated surface.

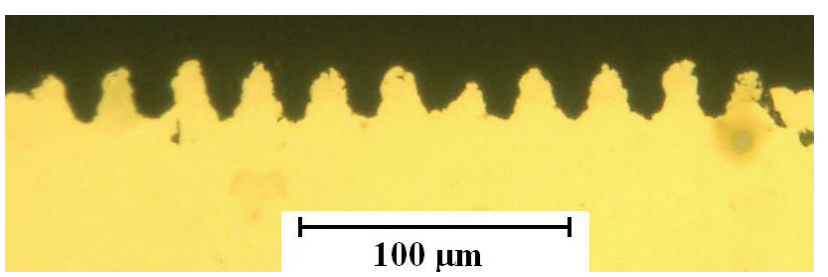

Fig. 17: Digital image of periodically ablated cavity structures, stainless steel, $\mathrm{v}=12,000 \mathrm{~m} / \mathrm{min}, \mathrm{P}=330 \mathrm{~W}, 15$ scans.

Previously, applying a scan speed of $900 \mathrm{~m} / \mathrm{min}$ separate micro walls of $37 \mu \mathrm{m}$ lateral distances were achieved $[1,2]$. With increasing scan speed, smaller lateral distances between the single lines were obtained accompanied by a significant higher resolution of the micro structures.

Fig. 18 illustrates an alternating wall - kerf micro structure with a depth of $50 \mu \mathrm{m}$, obtained after 60 scans. The widths of the kerf decrease up to $3 \mu \mathrm{m}$ due to re-deposition of molten material.

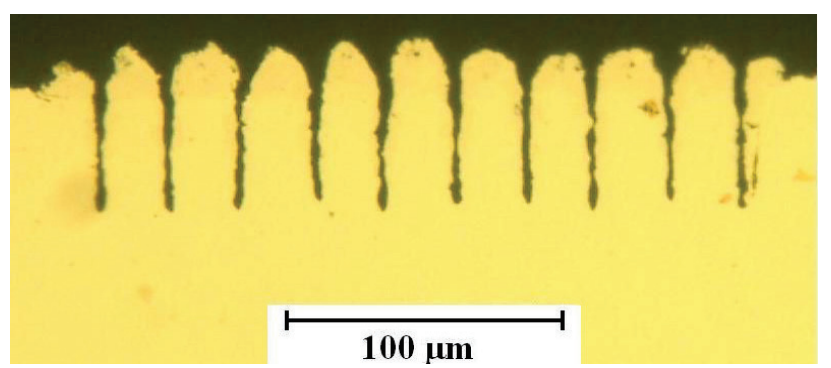

Fig. 18: Digital image of periodically ablated cavity structures in stainless steel, $\mathrm{v}=12,000 \mathrm{~m} / \mathrm{min}, \mathrm{P}=330 \mathrm{~W}, 60$ scans.

However, the mechanism of the laser energy input into the extremely small kerfs under irradiation of a laser beam with a laser spot size of $21 \mu \mathrm{m}$ is still under discussion.

\subsection{Applications}

\section{- Laser micro structuring of metal surfaces}

Fig. 19 illustrates a detailed micro wall array generated in stainless steel with a width of $35 \mu \mathrm{m}$, a lateral distance of $37 \mu \mathrm{m}$ and aspect ratio of $1: 3$. The area processing rate was $168 \mathrm{~cm}^{2} / \mathrm{min}$. A higher rate can be obtained with less scan numbers and lowered ablation depths.

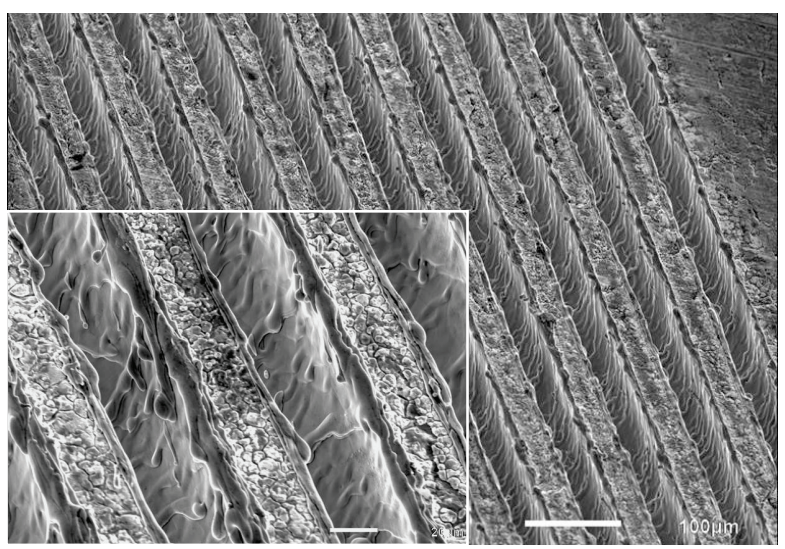

Fig. 19: SEM image of micro structured stainless steel surface, $\mathrm{v}=1,200 \mathrm{~m} / \mathrm{min}, \mathrm{P}=880 \mathrm{~W}, 5$ scans.

\section{- Thin film ablation}

Another approach studied ultra fast laser ablation of $2 \mu \mathrm{m}$ thick CrNi layer, deposited on a glass substrate (Fig. 20). Residue-free laser material ablation was achieved applying 2 laser scans with $0.88 \mathrm{~kW}$ laser power and a scan speed of $9,000 \mathrm{~m} / \mathrm{min}$. The area processing rate was determined of $2,250 \mathrm{~cm}^{2} / \mathrm{min}$. The high potential of the novel technology indicates an area processing rate of $4,500 \mathrm{~cm}^{2} / \mathrm{min}$, calculated for grid fabrication with a period of $100 \mu \mathrm{m}$.

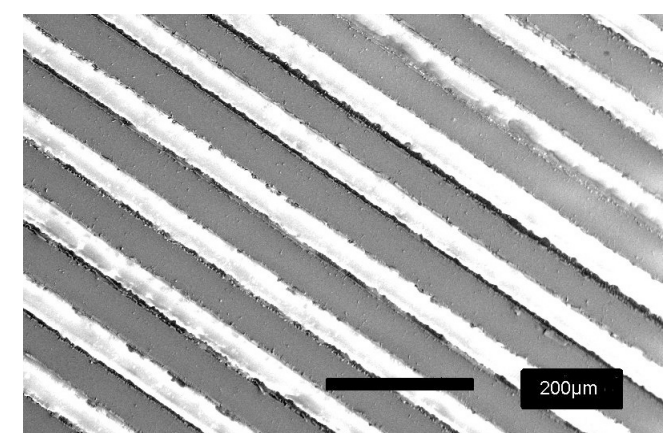

Fig. 20 SEM image, thin film ablation of NiCr layer, thickness: $2 \mu \mathrm{m}, \mathrm{P}=880 \mathrm{~W}, \mathrm{v}=9,000 \mathrm{~m} / \mathrm{min}, 2$ scans.

\section{- High speed laser cutting}

Application of the high speed ablation laser technology in laser ablation cutting enables high detailed outlines due to the short laser dwell times. Fig. 21 (left) illustrates an acute-angled outline with an edge radius of $30 \mu \mathrm{m}$ in stainless steel. On right side a machining example with a cutting length of $560 \mathrm{~mm}$ and $0.3 \mathrm{~mm}$ thickness is shown. The total processing time was $3 \mathrm{sec}$. according to an effective processing speed of $112 \mathrm{~m} / \mathrm{min}$. In contrast laser cutting of the structure using conventional laser cutting technologies and flying cutting optics takes at least ten times longer. 


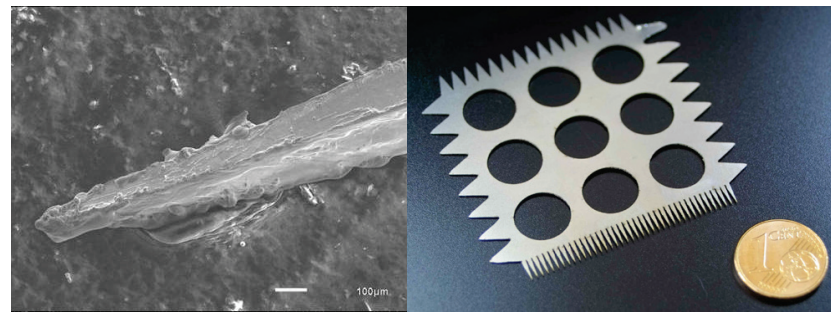

Fig. 21: left: SEM image of a tip with an angle of $5^{\circ}$ in stainless steel, $\mathrm{P}=1.76 \mathrm{~kW}, \mathrm{v}=600 \mathrm{~m} / \mathrm{min}, 2$ scans; right: processing example in stainless steel, thickness $0.3 \mathrm{~mm}$, scan length: $560 \mathrm{~m}$, 10 scans.

\section{Summary and outlook}

In the study, laser micro structuring using ultra fast scan speeds up to $18,000 \mathrm{~m} / \mathrm{min}$ joint together with high brilliant high power cw fibre laser was presented. Particularly in thin metal sheet processing with a thickness smaller than $100 \mu \mathrm{m}$, a high potential of the ultra fast technology can be assumed. Laser cutting of stainless steel and copper metal sheets of $50 \mu \mathrm{m}$ thickness were carried out with $700 \mathrm{~m} / \mathrm{min}$ effective cutting speed at $2 \mathrm{~kW}$ laser power; for tungsten the effective cutting speed was $540 \mathrm{~m} / \mathrm{min}$. Furthermore machining examples in laser micro structuring of surfaces, thin film laser ablation and high rate laser ablation were presented.

Prospective works will be themed on ultra fast beam switching of the high power cw laser radiation as soon as a more detailed scientific investigation of the interacting effects using high power cw lasers in high rate laser micro processing.

\section{Acknowledgments}

The authors wish to thank the BMBF for sponsoring the Innoprofile project "Rapid microtooling using laser-based methods" (Ministry ref. no. 03IP506). Furthermore we thank A. Fischer and F. Ospald for expert temperature field calculations.

\section{References}

[1] Hartwig, R.Ebert, F.Peuckert, S.Kloetzer, A.Streek, J.Schille, U.Loeschner, H.Exner: "HochleistungsLasermikrobearbeitung mit brillanter cwLaserstrahlung" (written in German), 20th International Scientific Conference Mittweida, Oktober 2829, Scientific Reports Nr. 4, 2009, S. 57-64.

[2] L.Hartwig, R.Ebert, S.Klötzer, S.Weinhold, J.Drechsel, F.Peuckert, J.Schille, H.Exner: Material processing with a $3 \mathrm{~kW}$ single mode fibre laser, Journal of Laser Micro / nanoengineering, Vol. 5, No. 2. (June, 2010), pp. 128-133.

[3] E.Beyer: "Fraction-Limited Fiber Lasers for Welding and Cutting", in CLEO/Europe and EQEC 2011 Conference Digest, OSA Technical Digest (CD) (Optical Society of America, 2011), paper TF1_2.

[4] J.P.Bergmanna, A.Patschgerb, A.Bastick, "Enhancing Process Efficiency due to high Focusing with high Brightness Lasers - Applicability and constraints", Physics Procedia, Volume 12, Part A, 2011, pp. 66-74.
[5] R.Ebert, L.Hartwig, F.Peuckert, S.Kloetzer, J.Schille, T. Hagemann, S.Wischmann, H.Exner: "High rate ablation with $3 \mathrm{~kW}$ single mode fibre laser", Proceedings of the 5. Int. WLT-Conference on Laser in Manufacturing, June 2009, Munich, Germany, pp. 565-570.

[6] A Mahrle, M Lütke, E Beyer: "Fibre laser cutting: Beam absorption characteristics and gas-free remote cutting", Proceedings of the Institution of Mechanical Engineers, Part C: Journal of Mechanical Engineering Science May 1, 2010 vol. 224 no. 5, pp. 1007-1018.

[7] G. Reisse, R. Ebert: "Titanium nitride thin film deposition by laser CVD”, Applied Surface Science 106 (1996), pp. 268-274.

[8] W. Elenbaas, Light Sources (Crane. Russak, New York, 1972), p. 22.

(Received: July 2, 2010, Accepted: January 6, 2012) 